\title{
A Hierarchical Biology Concept Framework: A Tool for Course Design
}

\section{Julia Khodor, ${ }^{* \dagger}$ Dina Gould Halme, ${ }^{* \dagger}$ and Graham C. Walker ${ }^{*}$}

*Department of Biology, 68-633, Massachusetts Institute of Technology, 77 Massachusetts Avenue, Cambridge, MA 02139

Submitted October 1, 2003; Revised April 2, 2004; Accepted April 6, 2004

Monitoring Editor: Bruce Alberts

\begin{abstract}
A typical undergraduate biology curriculum covers a very large number of concepts and details. We describe the development of a Biology Concept Framework (BCF) as a possible way to organize this material to enhance teaching and learning. Our BCF is hierarchical, places details in context, nests related concepts, and articulates concepts that are inherently obvious to experts but often difficult for novices to grasp. Our BCF is also cross-referenced, highlighting interconnections between concepts. We have found our BCF to be a versatile tool for design, evaluation, and revision of course goals and materials. There has been a call for creating Biology Concept Inventories, multiple-choice exams that test important biology concepts, analogous to those in physics, astronomy, and chemistry. We argue that the community of researchers and educators must first reach consensus about not only what concepts are important to test, but also how the concepts should be organized and how that organization might influence teaching and learning. We think that our BCF can serve as a catalyst for community-wide discussion on organizing the vast number of concepts in biology, as a model for others to formulate their own BCFs and as a contribution toward the creation of a comprehensive BCF.
\end{abstract}

Keywords: undergraduate, Biology Concept Framework, hierarchical, Biology Concept Inventory, misconceptions, course design.

\section{INTRODUCTION}

The idea of a Concept Inventory as an assessment tool dates back to 1992, when the Force Concept Inventory (FCI) was developed to measure students' conceptual understanding of motion and force (Hestenes and Wells, 1992; Hestenes et al., 1992). A major accomplishment of this work was to create a multiple-choice test in which the erroneous answers diagnose the misconceptions held by students about particular concepts. The FCI has been used over the past decade by physicists at several institutions of higher learning to assess the effectiveness of different teaching methods (Hake, 1998). Similar multiple-choice exams have been developed for astronomy (Astronomy Diagnostic Test [Zeilik et al., 1997; Deming, 2002; Hufnagel, 2002; Zeilik, 2003]) and chemistry (ConcepTests: http://chem.wisc.edu/ concept/).

Efforts to create similar standardized tests in biology are now under way. A group headed by Michael Klymkowsky at the University of Colorado at Boulder has been creating concept tests to cover "introductory, genetics, molecular, cellular, and developmental biology" (Klymkowsky et al., 2003).

\footnotetext{
DOI: $10.1187 /$ cbe.03-10-0014

${ }^{\dagger}$ Authors contributed equally.

‡Corresponding author. E-mail address: gwalker@mit.edu.
}

Dianne Anderson and colleagues (2002) have published a concept inventory of natural selection.

Before these tests can be useful for a variety of courses and institutions, there needs to be agreement as to which concepts are important. Bio2010: Transforming Undergraduate Education for Future Research Biologists, a report produced by the National Research Council (NRC, 2002), provides support for this effort, in stating that "understanding the unity and diversity of life requires mastery of a set of fundamental concepts" (Recommendation 1.1). Lists of biology concepts important for high school students can be found in the American Association for the Advancement of Science (AAAS) Project 2061 report Benchmarks for Scientific Literacy and the NRC report National Science Education Standards (AAAS, 1985; NRC, 1996). The NRC report Bio2010 and the Biology Concept Inventory Web site developed by Michael Klymkowsky and colleagues at University of Colorado at Boulder list concepts important for undergraduate students (NRC, 2002; Klymkowsky et al., 2003, http://www.bioliteracy.net). There is significant overlap between the concepts appropriate for the high school and those appropriate for the introductory-level undergraduate students.

The discussion about which concepts are important has been vigorous, but what has been lacking is a framework for organizing these concepts. For instance, all four of the lists 
cited above contain concept statements that can be further dissected into multiple sub-concepts. For example, the statement from Bio2010, "Most biological processes are controlled by multiple proteins, which assemble into modular units to carry out and coordinate complex functions," in fact contains several related yet separable concepts, such as (among others) (1) biological functions needing to be under some form of control and (2) proteins acting as the agents of that control in many cases. We submit that in order to test a concept with an instrument such as a Biology Concept Inventory, examiners need to be perfectly clear about which concept is being tested, and achieving such clarity is difficult with multicomponent concepts.

Thus, we constructed a Biology Concept Framework (BCF) to address these important issues. Our BCF is hierarchical and cross-referenced, and we believe there are significant benefits to this organization. Further, in developing our BCF, we wanted to construct an instrument that would be of immediate and practical use. We began by developing an institutional BCF tailored to our own specific educational needs, rather than a comprehensive BCF that spans the very broad range of biological knowledge. Therefore, we narrowed our focus to the core concepts covered in the three educationally equivalent versions of Introductory Biology as they are taught at the Massachusetts Institute of Technology (MIT) described further below. Since Introductory Biology is required of all MIT undergraduates, each course has two major populations of students: freshmen who intend to major in biology and students who are taking the course to fulfill a university-wide requirement (some of whom have an interest in learning biology and some who do not). As a result, these courses aim to prepare biology majors to perform well in subsequent biology courses while at the same time providing both majors and nonmajors with an intellectual framework with which to approach issues they may face as members of society.

We thought that developing a BCF tailored to our specific courses would help us refine our teaching of Introductory Biology at MIT, coordinate our different versions of Introductory Biology, and assess their effectiveness. However, we sought to design our BCF in such a way that its organization could be applied to the content chosen by an instructor regardless of the educational objectives of the course, and we hope it will serve as a catalyst for a community-wide discussion. We note that the material covered in our BCF has substantial overlap with that addressed by the four concept lists cited above, although there is some difference in the emphasis and level of detail.

Although we focused on MIT, any introductory biology course will have one, if not both, of the objectives outlined above. In addition, we hope that our BCF will stimulate a community-wide debate about (1) how important concepts can be broken down into subconcepts, (2) how to decide which concepts are essential or enhance the understanding of the whole, (3) how these concepts are to be organized, and (4) how they relate to each other.

In this paper, we describe the rationale for the design of our BCF and the process by which it was generated, as well as discuss its application both immediately and in the long term. A version of our hierarchical institutional $\mathrm{BCF}$, as of the time of publication, can be found at http:/ / web.mit.edu/bioedgroup/HBCF/CBE-Summer2004.htm.

\section{DEVELOPING A BIOLOGY CONCEPT FRAMEWORK}

\section{Educational Context}

Since 1993, Introductory Biology has been a required course for all MIT undergraduates. Because over 900 students take Introductory Biology at MIT each year, we have the opportunity to offer three educationally equivalent versions of Introductory Biology. All three versions of the course cover biochemistry, genetics, molecular biology, gene regulation, recombinant DNA technology, and immunology. The remaining time is spent on the areas chosen by the pair of professors teaching each version of the course. Thus, one version currently covers additional material concerning cancer, the nervous system, and genomics; another covers cancer and development; and the third covers ecology, additional biochemistry, and the genetics of microorganisms. Each course consists of 1-h lectures, delivered by professors three times per week, and 1-h small-group recitation sections, led by teaching assistants (TAs) twice per week. Each course also involves a full-time, postdoctoral-level instructor who plans recitation section, problem set, and exam materials.

The effort in constructing our BCF was made possible by an HHMI Professorship Award to G.C.W., which funded the creation of an Education Group, analogous to his research group. As part of the HHMI Education Group activities, postdoctoral associates D.G.H. and J.K. served as teaching assistants in one of the three versions of the Introductory Biology course at MIT. We were able to take the time to perceive the big picture of the class in terms of both the content and the organization and to think about realistic and incremental ways in which teaching and learning can be improved in the context of Introductory Biology at MIT.

\section{Motivation for Creating a BCF}

There are two major educational goals of the Introductory Biology courses at MIT. The first goal is to prepare biology majors to perform well in subsequent biology courses. The second goal is to create enduring understanding of key ideas by providing both majors and nonmajors with the tools with which to approach questions related to biology that they may face as members of society. This will additionally serve the majors by providing them with a framework for their future studies in biology. Understanding these ideas will serve students well, majors and nonmajors alike, when they are called on to make decisions personal or public (NRC, 1996). Currently, as noted in the NRC (1999) report Transforming Undergraduate Education in Science, Mathematics, Engineering, and Technology [SME\&T], " ... The understanding of SME\&T by most Americans, which reflects the level of SME\&T education most Americans have had, is inadequate for full participation in this increasingly technological world" (p. 1).

As members of the HHMI Education group, we were able to view course material as experts but, at the same time, interact closely with students who view the material through the eyes of a novice. A detailed description of the process of creating the BCF in provided below.

In exploring our students' difficulties, we often found that the root of their confusion did not stem from the particulars of the topics in questions but, rather, resulted from a lack of understanding of fundamental principles of biology. 
This observation has prompted us to organize the concepts and details covered in the courses into a hierarchical crossreferenced BCF. We imagined using our BCF as an aid to TAs, instructors, and lecturers. We hoped that highlighting the concepts central to each unit and the connections between the units would enable us to achieve both of our educational goals.

\section{Rationale for Design}

We limited the scope of our BCF to the content common to the three versions of Introductory Biology at MIT. Even when limiting ourselves to an institution-specific $\mathrm{BCF}$, the number of concepts to be considered was overwhelming. Thus, our first organizational decision was to sort through a vast array of ideas important to understanding the material in our courses and to place these ideas into a hierarchical structure. Such a hierarchy might classify ideas that are conceptually linked as belonging to distinct categories, so our second decision was to highlight the connections between ideas by crossreferencing them. We subsequently developed and refined these organizational features as described in more detail below. We feel that this organizational structure will help the students master the material covered in the course because an "expert's knowledge is connected and organized around important concepts" (NRC, 2000, p. 9).

We designed our hierarchical BCF to serve as a tool for course design, assessment, and revision. Such a BCF helps identify the important concepts one wishes to teach and design the course in a way that emphasizes connections between previously identified key concepts. A BCF would also allow for coordination of courses within or across departments by providing instructors with a hierarchical list of concepts and facts covered within each course-essentially a list of what the students can be expected to know, and be able to do, after taking each course.

Our thought process in structuring the BCF mirrors the "Establishing Curricular Priorities" method described by Wiggins and McTighe (2000, Fig. 1.2) in Understanding by Design. The authors argue that in developing any curriculum, an educator should prioritize the material into three levels of desired student understanding: knowledge worth being familiar with, important knowledge and skills, and enduring understanding. As suggested by its phrasing, the first level contains material that is helpful as background. The second level contains material that is necessary for students to master in order to accomplish key tasks that demonstrate full understanding of the enduring concepts at the third level. Wiggins and McTighe (2000) argue that "student learning is incomplete if the unit or a course concluded without mastery of these essentials" (p. 9). The third level contains truly key ideas, concepts we want students to "retain after they've forgotten many of the details," ideas that "go beyond discrete facts or skills to focus on larger concepts, principles, or processes." (p. 10).

We see the top-level concepts in the BCF as equivalent to those at the enduring understanding level of the above structure. In fact, we would argue that these top-level concepts should withstand the scrutiny of the following filter: for any topic taught in Introductory Biology, we might ask whether it is worth an educated citizen knowing and whether having known it as a student empowers a person to make more in- formed and reasoned decisions when voting (paraphrasing Bruner, 1960, p. 52).

Consequently, in the context of our Introductory Biology class, we see Level 1 of our hierarchy as corresponding to the enduring understanding level above, Levels 2 and 3 as corresponding to the important knowledge and skills, and Levels 4 and below as corresponding to the knowledge worth being familiar with. However, it can be argued that to be successful in their academic careers, future biology majors would be well served to shift the boundary of the enduring understanding category to include Level 2 ideas and to expand the important knowledge and skills category to include some of the Level 4 ideas. In fact, as biology students progress through their studies, the boundaries of the categories of understanding are continually shifted down through the levels of our hierarchy. The usefulness of this approach can be tested by assessing the levels of understanding by students at various stages of their academic careers and determining how this correlates with their levels of success.

As mentioned above, the scope of the material covered in our BCF is limited not only to Introductory Biology as it is taught at MIT, but also to the material common to the three versions of the course. As a result, some sections of the BCF are particularly sparse in their coverage. For instance, the MIT courses focus on the molecular and cellular levels and therefore section 18 of the BCF only touches on the development of tissues and systems. Other courses could expand the content supporting the top-level idea as is appropriate for their educational goals.

\section{Steps in the Process}

D.G.H. and J.K. began the process by listing the concepts covered in the course based on lecture and recitation section notes, exam problems, and our experiences interacting with students. We formulated our lists separately and then compared and merged them. Upon review of the lists, we decided that the final BCF should be a hierarchical structure with cross-references. We felt that this format most naturally reflected the flow of interconnected ideas within and across the units of the course. As a result, we formulated a number of top-level concepts and organized some supporting concepts.

The next phase of the development included a larger group of people. We held two Education Group meetings 3 wk apart. We asked the other members of the group (which includes graduate students, postdocs, instructors for Introductory Biology and other courses in the department) to come to the first meeting with their ideas on what concepts are important within the context of an introductory biology course. The group members presented their lists and then commented on and helped expand our original list of central concepts in the course. Discussion at the meeting highlighted the areas that we had neglected in the first listing, resulting in the expansion of the list. For instance, top-level Concept "5. Cells interact with other cells" was added. By the end of the meeting we reached consensus on which concepts fall into the top category. The debate that led to this consensus helped us appreciate other viewpoints and incorporate them into future steps of the BCF's development.

The process of BCF creation and refining then proceeded in rounds. Each iteration consisted of core-group (D.G.H. and 
J.K.) document refining followed by larger-group document critique. After the first large meeting, we expanded and revised our BCF draft, each concentrating on different sections but providing the other with continuous feedback. Several times through the process we took a step back to assess the overall situation and to make sure that our list of top-level concepts conformed to the project principles as originally stated. This usually resulted in reformulating one or more top-level concepts and, on occasion, in adding or removing a concept from the top level. For example, we moved Concept "10-1. Sexually reproducing diploid organisms get one copy (allele) of each gene from each parent and pass one allele on to each of their offspring at random" from the top-level to its current location under Concept "10. Sexual reproduction is a powerful source of variation." Throughout this stage of the process we received guidance from the Introductory Biology instructors about the relative importance of various topics and concepts.

The second meeting of the Education Group concentrated on critiquing the then-current draft of the BCF in light of three questions: 1) Are there any essential concepts not currently on the list? 2) Is there anything on the list that does not belong or is in the wrong level of the hierarchy? and 3) Are there any particular phrases that need rewriting?

The meeting was attended by over a dozen people, including members of the Biology Department and professors and researchers from the Electrical Engineering and Computer Science Department who are interested in interdisciplinary collaborations and educational efforts. The variety of perspectives was very helpful in refining the BCF. For example, we added Concept "11-1. Life obeys all the laws of chemistry and physics" as suggested by one of the nonbiologists present. One of the recurring themes of the meeting was that the BCF demonstrates that we expect our students to learn an enormous number of concepts, ideas, and facts and that, if we are serious about them learning this volume of information, we need to be systematic and conceptual in our approach to teaching.

After editing the $\mathrm{BCF}$ to reflect the discussion at the second Education Group meeting and reaching internal consensus, we asked the professors teaching the three versions of the Introductory Biology for their feedback on the document. These lecturers were able to refocus the BCF to the material specific to Introductory Biology as taught at MIT. For example, as a result of one of the faculty's comments, we formulated Concept "6-4-1. Differentiation usually involves the selective reading of a genome rather than a change in the sequence of the genome."

In December 2003, we conducted another meeting of the Education Group focused on editing the top-level concepts of the BCF. We feel that the clarity and precision of the toplevel concepts improved yet again due to the synthesis of ideas of the 16 people in attendance. For example, Concept 7 used to read "DNA is the source of information in a cell." As a result of the meeting, we have changed it to the more precise formulation "DNA is the source of heritable information in a cell."

We have used our BCF as an aid to the TAs in the Fall 2003 version of the Introductory Biology and as a guide in designing the supplementary laboratory component to this class. As a result of our experience, we revised and supplemented the document to incorporate informal feedback from under- graduates. We now believe that the BCF will remain a work in progress for the foreseeable future as we integrate new knowledge, revise the phrasing of concepts, and supplement cross-referencing to better address problem areas in student understanding.

\section{THE STRUCTURE OF OUR BIOLOGY CONCEPT FRAMEWORK}

\section{Top-Level Concepts}

In our BCF, the top-level concepts (Level 1) serve as umbrella ideas encompassing many of the more complicated and detailed concepts that we teach in Introductory Biology. As discussed above, these concepts went through various iterations until they were agreed on by the HHMI Education Group. Table 1 lists the top-level concepts that emerged from this process. The concepts must be written down in some linear order for practical purposes, but we do not intend the numbering to be a ranking system that indicates relative importance. Instead, we consider either that all Level 1 concepts are equally important or that it is up to the individual instructor to decide on their relative importance. The Boyer Commission report calls for faculty to define their learning goals for a class (Wood, 2003), and we think that our Level 1 concepts could serve as a starting point for selecting these goals.

To make our Level 1 concepts as useful as possible to students, we have deliberately avoided the use of specialized scientific terms to the greatest extent possible. As can been seen in Table 1, the overarching principles are written primarily in natural language that can be understood by most students prior to taking an Introductory Biology course. It would be interesting to investigate how a student's perceived understanding of the language of a concept statement relates to his or her actual understanding of the concept described in the statement.

\section{A Multilevel Hierarchical Organization}

The next levels of our BCF fill in the concepts and details supporting each Level 1 concept. The underlying concepts and details are organized in a hierarchical structure as well. For example, in Table 2, an excerpt from the current version of our $\mathrm{BCF}$, we begin with the unifying principle that DNA is the source of heritable information in a cell (Concept 7). We then provide the supporting information that DNA is able to perform this role because it encodes the amino acid sequence of proteins, as well as multiple other levels of information (Concepts 7-1 and 7-2). Each of these concepts is then supported by information about its mechanism. For example, DNA can encode the amino acid sequence of a protein because sets of three letters in the nucleic acid alphabet specify one letter in the protein alphabet (Concept 7-1-1).

The foundation for this hierarchy of concepts is provided by facts and details. Concept 7-1-1-1 introduces the term codon and provides the details concerning how codons are involved in the initiation and termination of translation. This level of detail is important for the students who will continue to study biology because experts draw on a body of 
Table 1. Top-level concepts in the BCF

1. Biology is based on observational and experimental science.

2. At the molecular level, biology is based on three-dimensional interactions of complementary surfaces.

3. The cell is the basic unit of life.

4. All cells share many processes/mechanisms.

5. Cells interact with other cells.

6. Cells are created from other cells.

7. DNA is the source of heritable information in a cell.

8. A gene is the functional unit of heredity.

9. The structure of DNA dictates the mechanism of the production of nucleic acids and proteins.

10. Sexual reproduction is a powerful source of variation.

11. Life processes are the result of regulated chemical reactions.

12. Proteins perform many varied functions in a cell.

13. Recombinant DNA technology allows scientists to manipulate the genetic composition of a cell.

14. The expression of genes is regulated.

15. All carbon-containing biomass is created from $\mathrm{CO}_{2}$.

16. Populations of organisms evolve because of variation and selection.

17. Organisms and the environment modify each other.

18. In multicellular organisms, multiple cell types can work together to form tissues which work together to form organs.

Numbering is for practical purposes and does not indicate relative importance. Natural language is used to formulate the organizing concepts.

specific knowledge when solving problems (NRC, 2000). To develop competence as defined in How People Learn, students must "a) have a deep foundation in factual knowledge, b) understand facts and ideas in the context of a conceptual framework, and c) organize knowledge in ways that facilitate retrieval and application", (p. 16). We feel that our BCF has the potential to be an excellent teaching and learning tool because it provides facts (Level 4), puts them in a conceptual framework (Levels 1-3) and or- ganizes this knowledge (hierarchical structure and crossreferencing).

\section{Benefits of the Hierarchical Structure}

Table 3 depicts a more complex segment of the BCF that further highlights the benefits of its organization. First, the hierarchical structure of the BCF forced us to articulate some of the underlying themes in biology as they relate

Table 2. Concepts are organized into a nested hierarchy based on relative importance

7. DNA is the source of heritable information in a cell.

7-1. The amino acid sequence of proteins is encoded in DNA.

7-1-1. Sets of three letters in the nucleic acid alphabet (sets of four letters) specify one letter in the protein alphabet (sets of 20 letters). 7-1-1-1. 64 triplet codons: ATG initiating methionine, three Stop codons, 60 other codons for the remaining 19 amino acids.

7-2. Information is encoded in DNA, using different languages that are recognized by different machinery.

7-2-1. DNA encodes when a gene will be expressed or not.

7-2-1-1. DNA sequence: promoter, operator, enhancer.

7-2-1-2. Protein machinery: activator, repressor, transcription factors.

7-2-2. DNA encodes the point at which replication begins.

7-2-2-1. DNA sequence: origin of replication (ori).

7-2-2-2. Protein machinery: origin recognition complexes.

7-2-3. t-RNA acts an adaptor to translate the nucleotide sequence into an amino acid sequence.

7-2-3-1. The anticodon of a t-RNA is complementary and antiparallel to the codon it binds.

7-2-3-2. Ribosomes are responsible for bringing the mRNA and $t$-RNA together and catalyzing the formation of peptide bonds.

7-2-4. DNA encodes the information to properly segregate chromosomes during cell division.

7-2-4-1. DNA sequence: centromere.

7-2-5. DNA encodes the cellular address of each protein.

7-2-5-1. DNA sequence encodes: nuclear localization signal, mitochondrial uptake sequence, signal sequence, and transmembrane domain.

7-2-5-2. Protein machinery: receptors bind these amino acid sequences and localize proteins accordingly.

7-2-6. DNA encodes: restriction endonucleases recognition sites.

7-3. When DNA is mutated, the information it contains may be changed.

7-3-1. Because DNA can encode amino acid sequences, the structure and therefore the function of proteins may be changed.

7-4. Segments of DNA that contain all of the information to encode the sequence of a product and regulate its expression are called genes. 7-4-1. The DNA that comprises an organism's genome is organized into chromosomes.

Attempts are made to use as little technical terminology and as much natural language as possible in the upper levels of the structure. 
Table 3. A cross-referenced section of the MIT institutional BCF

6. Cells are created from other cells.

6-1. Cell formation by spontaneous generation has never been observed. See 3-2-1.

6-2. As a result of cell division, one cell becomes two.

6-2-1./3-1-1. Before a cell divides, all of its machinery is duplicated.

6-2-2. When eukaryotic cells divide, DNA replication followed by chromosomal segregation in mitosis $(2 n \rightarrow 4 n \rightarrow 2 n)$ ensures that the daughter cell has the same genetic information as the mother cell.

6-2-3. The complementary base-pairing of DNA molecules allows for a built-in duplication mechanism. See 9-1-3.

6-2-3-1. Two molecules of DNA are created from one, by semiconservative replication.

6-2-3-2. Each of these new molecules goes to a daughter cell. Therefore, one mother cell gives rise to two daughter cells.

6-2-4. Prior to cell division, all essential cellular machinery is duplicated and segregates into future daughter cells. See 3-1-1/6-2-1.

6-3. In sexual reproduction, two gametes join to form a zygote.

See 5-6, 10-1, 16-1-3.

6-3-1. Each gamete carries half the genetic complement of a cell. See 10-1-3.

6-3-1-1. A gamete carries a haploid set of chromosomes. See 10-2-2.

6-4. One cell division can give rise to two cells that will differentiate into two distinct cell types, serving two distinct functions.

6-4-1. Differentiation usually involves the selective reading of a genome rather than a change in the sequence of the genome. See 7-4, 8-2, 11-2-1, 12-7-1, 14-1, 14-1-2, 14-3-1.

6-4-1-1. Two cells that result from one division, and have the same genetic material can have different morphology and behavior due to differentiation - expressing a different set of genes to perform a different function in the organism. See 12-7-1.

6-4-2. Terminally differentiated cells (that are capable of division) can only give rise to cells of the same type as self.

6-4-3. In multicellular organisms, pluripotent (stem) cells have the potential to differentiate into many different cell types.

6-4-3-1. Whole animal cloning seeks to create the original pluripotent cell-an embryo, using the nucleus of a differentiated cell. See 13-3-1-6.

Cross-references to other sections of the BCF after several of the concepts.

to our courses. Upon examination of our Introductory Biology courses with the BCF in mind, we discovered that some ideas, although pervasive, were not articulated or emphasized to a degree proportional to their high level of importance. We regard the top-level concept, "6. Cells are created from other cells" (Tables 1 and 3), as such an underappreciated concept. While many hours of class, section, and homework time are spent making sure the students understand such specialized topics as the mechanism of semiconservative replication, complete with Okazaki fragments, few students have been asked to think about whether spontaneous cell generation will occur if all the necessary molecular components are mixed together in a test tube. Fewer still have been prompted to consider the logical chain that connects Concept 6 and Concept "6-2-3-1. Two molecules of DNA are created from one, by semiconservative replication" (Table 3 ). It is our hope that when the hierarchical BCF is used as a tool in the MIT Introductory Biology courses, points like these will be explored, and student comprehension improved.

Second, the hierarchical structure of the BCF enables not only the ranking of concepts in terms of their levels of importance, but also the placement of concepts in their proper contexts. For example, without any context, it may be difficult to understand how two cells that have the same genetic material can have different morphology and behavior (Concept 6-4-1-1). However, if this concept is placed in the context of a concept that states, "Differentiation usually involves the selective reading of a genome..." (Concept 6-4-1) it becomes clearer how one set of information can give two different outcomes. The Level 2 concept above provides the rationale for why differentiation is important.

Third, the hierarchical structure allows us to place details in the context of concepts. Simply by nesting facts in the hierarchy we are providing a context for these details that will help the students not only remember them but also understand why they are important. For example, in Table 4 we list the details that "recombination occurs during meiosis, after the DNA has been duplicated, and the homologous chromosomes are lined up" (10-2-3-1). Each of these pieces of information may seem trivial or difficult to understand or remember on its own, but when related to the context provided one level up ("10-2-3. Recombination-the exchange of parts of chromosomes between homologous pairs of chromosomes-increases the rate of reshuffling of parental genetic information..."), the details provide the mechanism for how recombination works within the context of why it is important. If the DNA is duplicated prior to recombination, there is a greater variety of gametes generated than if recombination preceded duplication; the sister chromatids must pair up because recombination only occurs between homologous DNA sequences.

Research in the area of human learning has shown that "the construction and reconstruction of meaning by learners requires that they actively seek to integrate new knowledge with knowledge already in their cognitive structure" (Novak, 2002). Therefore, we need to make sure that the students have the proper cognitive structure in which to place newly learned details. If "some of the meanings constructed are faulty or limited ... this can distort or impede new meaning construction" (Novak, 2002).

\section{Benefits of Cross-Referencing Within A Hierarchy}

As illustrated in Table 3, cross-referencing allows us to emphasize the interconnections among various areas of biology. Sometimes, it is appropriate to state the same concept with different emphasis to support two different higher-level concepts and thereby connect them. For example, Concept "6-3-1. 
Table 4. Placing essential details into the lower levels of the hierarchy provides them with a context that makes them easier to understand

10. Sexual reproduction is a powerful source of variation.

10-1. Sexually reproducing diploid organisms get one copy (allele) of each gene from each parent and pass one allele on to each of their offspring at random. See 8-3.

10-1-1. One exception is sex-chromosome encoded genes in males.

10-1-2. Alleles are passed on to offspring without respect to the phenotype they confer.

10-1-3. An individual only passes one allele of each gene to its offspring. See 6-3-1.

10-1-3-1. Exception in 10-1-1 here applies for males and females.

10-1-3-2. The phenotype of an individual depends on the combination of alleles from both parents. 10-1-3-2-1. See exception in 10-1-1.

10-1-4./16-4-1. Only mutations in germ line cells will be passed on to the offspring. See 6-3, 10-2-2.

10-1-5. Somatic mutations are passed on to any descendants of the mutated cell within the organism, and can cause non-inherited disease.

10-2. Diversity is introduced in gamete formation.

10-2-1. Sexual reproduction allows for great diversity and fast change (through bringing together genetic information from two parents). See 6-3.

10-2-2. Gamete production in meiosis $(2 n \rightarrow 4 n \rightarrow 2 n \rightarrow n)$ allows for reshuffling of parental genetic information through independent segregation of chromosomes. See 10-1-2.

10-2-3. Recombination - the exchange of parts of chromosomes between homologous pairs of chromosomes-increases the rate of reshuffling of parental genetic information compared to 10-2-2 alone. See 8-8.

10-2-3-1. Recombination occurs during meiosis, after the DNA has been duplicated and the homologous chromosomes are lined up.

Each gamete carries half the genetic complement of a cell" is an explanation of why in sexual reproduction, two gametes need to join to form a zygote (Concept 6-3), which is one mechanism of creating cells from other cells (Concept 6). The idea expressed in Concept 6-3-1 can also be formulated as "10-1-3. An individual only passes one allele of each gene to its offspring." With this emphasis, the concept supports "10-1. Sexually reproducing diploid organisms get one copy (allele) of each gene from each parent and pass one allele on to each of their offspring at random, " which is one source of variation (Concept 10, Table 4). A further benefit of crossreferencing related concepts is that it enables us to reinforce a point in multiple contexts. Project 2061 contends that "concepts are best learned when encountered in a variety of contexts and expressed in a variety of ways, for that ensures that there are more opportunities for them to become embedded in a student's knowledge system" (AAAS, 1989, Chapter 13, p. 2).

Interconnections between concepts can also be depicted as concept maps. Concept maps are generated by graphically connecting related terms or concepts to each other using modifier words. The process of linking ideas together in such diagrams allows the learners to visually map the relationships between the parts. Furthermore, assessment of the maps that students make can be used to identify misconceptions or gaps in student understanding (Novak, 2002). An innovative computer program that enables students to take sets of terms and concepts and make their own maps was created at Michigan State University and can be found at http:/ / ctool.msu.edu/ctools/index.html. Concept maps are also used to present the framework of a complex web of ideas. For instance, the key concepts outlined in the AAAS publication Project 2061: Benchmarks for Science Literacy are organized into concept maps in the companion publication Atlas for Science Literacy (AAAS, 1985, 2003). We have chosen to represent the relationships between the concepts in our BCF as crossreferences that are hyperlinked.
The combination of placing concepts and details in context and then cross-referencing them allows us to group concepts logically rather than by course topic. For example, although mitosis and meiosis are covered in the same chapter in some widely used Introductory Biology textbooks (e.g. Purves et al., 2001; Audesirk et al., 2002; Solomon et al., 2002) and share many features, the end result and consequences for a cell undergoing these processes are very different. With this in mind, we place mitosis and meiosis under different toplevel ideas. Chromosomal segregation in mitosis (6-2-2) is the logical foundation for the concept of each mother cell giving rise to two daughter cells (6-2). Concept 6-2 in turn is one of the supporting ideas for the top-level concept " 6 . Cells are created from other cells." The idea of sexual reproduction as a mode of creating new cells also belongs with top-level Concept 6 and is therefore highlighted in Concept "6-3. In sexual reproduction, two gametes join to form a zygote." However, meiosis also results in the creation of genetic variation via sexual reproduction and this idea is not central to Concept 6 . Rather it is emphasized in Concept "10. Sexual reproduction is a powerful source of variation" (see Table 4). Since meiosis results in random assortment of chromosomes and, therefore, increases variation, its mechanism fits better as a Level 3 idea under "10-2. Diversity is introduced in gamete formation."

\section{RESULTING CHANGES IN HOW AND WHAT WE TEACH}

\section{Making Top-Level Concepts Explicit}

Wiggins and McTighe (2000) argue that teachers are designers, and that "[their] work as designers is complicated by the gap between expert and novice" (p. 21). Teachers face the challenge of knowing their students well enough to know what needs to be uncovered from the point of view of novices. In the process of formulating the top-level concepts, we were mindful of the student perspective and aimed to capture ideas 
pervasive to the MIT courses that had not been previously directly articulated, for example, top-level Concepts 1 and 2 in our BCF (Table 1).

Bio2010 states that, "many science ... courses are taught as sets of facts, rather than by explaining how the material was discovered or developed over time.... Demonstrating the process of discovery, or presenting other stories as examples of how scientists work ... is an excellent way to engage undergraduates" (NRC, 2002, p. 3). Many classical experiments are described in lectures in the MIT courses. However, what constitutes a well-designed scientific experiment, for example, what controls are and why they are needed, is rarely specified. The process of formulating hypotheses based on the data, and of designing experiments to differentiate between these hypotheses, also needs to be articulated and given greater prominence in our course.

Similarly, while many examples of the role of intermolecular binding in determining functions are presented (from a DNA polymerase binding DNA to initiate replication, to Lac repressor binding lac operator to prevent transcription of the genes of the lac operon, to antibodies binding antigen), the overarching principle that all processes in biology happen because of physical interactions of molecules binding each other is not emphasized in our class at the time when the details of these biologically important molecular interactions are discussed.

Observing that these key ideas are not made explicit in the course prompted us to formulate top-level Concepts 1 and 2. We were also stimulated to design two activities to increase students' awareness of these concepts.

First, to emphasize the experimental nature of biology early in the course, we have adopted the exercise designed by Mariëlle Hoefnagels (2002) for use on the first day of recitation section. The goal of this "design an experiment" exercise is for students to experience how scientists approach problem solving and to prepare them to understand the importance of a controlled experiment in generating much of the material they will encounter during the course.

The idea of the exercise is to provide students with everyday maxims or adages to use as hypotheses and to have them formulate experiments with controls to test these hypotheses. For example, students might propose to test the hypothesis that one will go blind if one sits too close to the TV by monitoring the eye health of a group of volunteers who report sitting close to their TVs. An instructor might then prompt the students to design appropriate controls or suggest alternative explanations for the putative decrease in the eye health of the observed group. These alternative hypotheses might include family history of eye disease, lack of proper nutrition, poor study habits, and sitting too close to the computer. The instructor could also encourage students to separate cause from effect by exploring whether sitting close to the TV results from having poor eye sight or whether sitting close to the TV results in poor eyesight. By designing and refining their proposed experiment, students are exposed to the issues involved in designing a good experiment and thinking critically about interpreting information.

The importance of this skill is emphasized in Science for All Americans, which claims that developing such "scientific habits of mind can help people in every walk of life to deal sensibly with problems that often involved evidence, quantitative considerations, logical arguments, and uncertainty; without the ability to think critically and independently, citizens are easy prey to dogmatists, flimflam artists, and purveyors of simple solutions to complex problems" (AAAS, 1989, p. 2).

A breakout session during the Reinvention Center Conference in November 2002 discussed the Boyer Report's call for more undergraduates to be involved in research. As William Wood (2003) reports, the group decided that "while 100\% participation in research was not a realistic or desirable goal," emphasis should be placed on students developing the "mindset of researchers" (italics his). After introducing students to the research mindset, via the exercise described above this thought process is reinforced via the presentation of classic experiments in lecture and assignment of problem set and exam questions involving experimental design or the interpretation of experimental data. In subsequent semesters we plan to assess what impact, if any, changes in our teaching approach have had on student learning.

Second, to reinforce the importance of the physical interaction of molecules as the underlying mechanism of all processes in a cell, we designed and implemented a novel activity that we named "The Shape Game" in the Fall semester of 2003. The game involves using manipulatives (objects) representing tertiary and quaternary structure of protein complexes. The goals of the game are fourfold: (1) to clarify that binding is the mechanism by which all information is transmitted; (2) to demonstrate that change in shape can prevent binding and therefore affect function; (3) to demonstrate that complementary mutations that restore binding can restore function; and (4) to demonstrate that proteins must maintain shape with respect to the next binding partner (point of transmission of information) in order to maintain function. While selfassessment surveys indicated that the students enjoyed the activity and felt it was beneficial to their understanding of the nature of protein interactions, we do not yet have quantitative data to indicate whether any gain in understanding was achieved. During the Fall term of 2003, we conducted preand post-activity concept-based surveys and will use these in addition to the exam data from the Fall semester, and a repeat use of the activity in the Spring semester to analyze its effectiveness. We are currently redesigning the shapes based on our practical experience. We will report the results of this work separately.

\section{Highlighting Concepts and Placing Details in Context}

While assembling our BCF, we identified a number of cases when our Introductory Biology courses emphasized details of specific examples rather than highlighting the concepts illustrated by the examples and failed to place these details in the larger context of the course. A topic that we consider particularly vulnerable to such treatment is gene regulation.

Like many introductory courses, we use the lac operon as a general example of gene regulation. We describe the negative regulation of the lac operon genes by the Lac repressor and then ask students to solve a variety of analogous problems in haploid and diploid systems. In discussions with students, we have found that many consider the whole topic merely a torturous exercise in solving problems, the purpose or logic of which they do not understand. They do not understand why they should care about what they consider an 
obscure prokaryote-specific phenomenon of organizing genes into operons.

We have responded to this dissatisfaction and confusion in several ways. First, we formulated Level 1 Concept "14. The expression of genes is regulated" to provide a context for why the lac operon example is important. Second, we highlighted the concepts demonstrated by the lac operon example rather than the details. Through discussions with struggling students, we have found that their confusion often stems from not seeing the role of the Central Dogma in gene regulation. Helping students understand that Lac repressor is a protein that is the product of lacI, and that lacI is a gene with its own promoter, can clear up students' confusion. To help the TAs make this connection when discussing gene regulation with their students, we articulated Concept 14-2, which essentially states that proteins regulate the production of proteins.

We also formulated Concept "14-3. Components of processes that work together are often regulated together" to provide a general statement of a phenomenon of which the lac operon is an example. After being placed in context by the Level 1 and 2 concepts above, Concept "14-3-1-1. Coregulated genes can be organized into operons or share common transcription factors and their consensus binding sites" makes sense as an essential part of our understanding of the workings of the biological systems. Details of the workings of the gene regulatory systems are addressed by other Level 3 and 4 concepts.

The factual information conveyed is the same whether the course is taught with or without using a hierarchical BCF for guidance. The difference between the two factually equivalent styles of teaching comes from the conceptual framework in which the facts and details about the workings of the gene regulatory systems are presented when the hierarchical BCF is used as a guiding principle. It has been our experience that students who understand the role that the Central Dogma plays in analyzing gene regulatory systems have a better grasp on both the concepts and the details of gene regulation. The importance of context in organizing and retaining new information has been known for over 70 years. As early as 1929, Whitehead had shown that when a detail is not presented in a useful context, the detail becomes "inert" and essentially useless. In contrast, "organizing facts in terms of principles and ideas from which they may be inferred is the only known way of reducing the quick rate of loss of human memory" (Bruner, 1960, pp. 31-32). Research since then supports this emphasis on the critical role of a conceptual framework in creating lasting understanding (SUNY et al., 1980; Waern, 1981; Cavallo, 1992; Oliver and Oliver, 1997; NRC, 2000; Mayer, 2002).

To improve our students' appreciation of the proper conceptual context of particularly detail-rich subject areas, and to improve their ability to synthesize the concept that is supported by these details, we have developed a series of simple animations. We have found that using our hierarchical BCF to focus our thinking to the important aspects of each subject area, we were able to tailor our animation design to emphasize the key ideas rather than the details. For example, our Gene Regulation animation does not dwell on the minute details of the lac operon regulation, but, instead, emphasizes the conceptual loop between genes and their products and the control of other genes and their products. Our Gene Regulation animation can be found at http://web.mit.edu/bioedgroup/animations. htm.

\section{FUTURE DIRECTIONS AND CONCLUSIONS}

\section{Expansion of the BCF}

We have created a BCF that represents the concepts covered in the core of the three educationally equivalent MIT Introductory Biology courses. However, as a consequence of the hierarchical structure of our BCF, concepts covered in upperlevel courses can be easily incorporated into the BCF. For example, in Table 4, Concept "10-2-3-1. Recombination occurs during meiosis, after the DNA has been duplicated and the homologous chromosomes are lined up" is the deepest level of technical detail. If Section 10 of our BCF were to be used by the instructors of the departmental undergraduate genetics course, the particulars of Holliday structures as a physical mechanism of recombination could be placed at Level 5 of the framework. As levels are added to the BCF by each course, the boundaries of what falls into each of the three categories of understanding (enduring understanding, important knowledge and skills, and knowledge worth being familiar with), as described above, can shift accordingly.

Annotating our BCF would also allow us to expand the scope of the document to include references to concepts and facts from other fields of human knowledge. In the context of an institution, one can indicate which course might address a related concept. For example, at MIT, we might additionally reference the introductory chemistry course when discussing the five molecular forces in our BCF. One might even imagine eventually creating institutional concept frameworks in multiple fields and crossreferencing these frameworks to include applicable concepts found in all of them.

\section{BCF-Related Projects}

Having created a working draft of the MIT BCF, we plan to use it in several related projects. First, beginning with one of the two versions of Introductory Biology taught in the Spring semester of 2004, we plan to incorporate the principles and insights gained in creating the BCF and assess the impact of this new approach. It is important to decide early on what we would "accept as evidence that students have attained the desired understandings and proficiencies" (Wiggins and McTighe, 2000, p. 8). A wealth of information on various instruments designed to measure understanding is available at the Field-Tested Learning Assessment Guide Web site (http://www.flaguide.org) from the National Institute for Science Education at the University of Wisconsin. While some of these Classroom Assessment Techniques (CATs), such as the Student Assessment of Learning Gains (http://www.wcer.wisc.edu/salgains/instructor), focus on student perceptions of the benefit derived from a particular educational experience, many, such as ConcepTests (Landis et al., 2001), concept mapping (Novak, 1998), conceptual diagnostic tests (http://www.flaguide.org/ cat/diagnostic/diagnostic1.htm), and performance assessments (Shavelson et al. 1991), are designed specifically to test conceptual understanding. We think that because our $\mathrm{BCF}$ articulates and organizes concepts, it would provide a valuable resource for faculty seeking to apply any of these concept-based assessment methodologies. 
As the first step in the direction of concept-based assessment, we plan to pose conceptual questions at the beginning of each unit. The questions will highlight the important concepts and their relationships as formulated by our BCF. One facet of our assessment will focus on determining whether students have grasped these big ideas by the end of the semester. To analyze the students' comprehension, we plan to write questions for the regular exams that will directly test the concepts from the BCF. By mapping specific concepts to specific questions, we can make sure that we are testing what we think is important and then determine whether we have been successful at conveying the concepts.

Second, over the next several semesters, we plan to use the BCF as a tool to investigate student misconceptions. As has been learned by the extensive research in the teaching of physics (Halloun and Hestenes, 1985), identifying and directly confronting student misconceptions are an essential part of effective teaching. "People construct new knowledge and understandings based on what they already know and believe ... [therefore] teachers need to pay attention to the incomplete understandings, the false beliefs, and the naive renditions of concepts that learners bring with them to a given subject" (NRC, 2000, p. 10). We intend to use the BCF as an organizing structure to help the teaching assistants, who have the most direct contact with the students, to identify misconceptions and link them back to the concepts that we aim to teach. We hope to develop pre- and post-tests, or possibly use the final exam as a post-test, to unearth more of these misconceptions. The current format of our exams is mostly short answer questions. This format is conducive to unearthing student misconceptions, but only if correct answers require conceptual understanding rather than memorization. The misconceptions unearthed in this process would then aid us in developing formative assessment tools for use in future semesters.

Third, we are interested in determining if there is a correlation between the probability a student will retain a given concept in the long term and its position in the hierarchy of our BCF. Introductory Biology is the only formal educational exposure many students will have to this important subject that will have a major impact on so many aspects of their lives. Regardless of how well students perform on our exams, it is realistic to expect that they will not retain much of the detailed information they learn unless they are exposed to it again in subsequent courses or need to use it in their careers. One of our goals for the course, in keeping with Science for All Americans, is that we hope that people remember certain concepts after they have forgotten all the details. We hypothesize that students are more likely to remember Level 1 concepts than they are to remember Level 3 concepts. An instrument like the basic bioliteracy BCI currently under construction by the Klymkowsky group at UC Boulder could be used to test this conjecture (Klymkowsky et al., 2003). We are investigating the possibility of assessing retention of key concepts by a cross section of MIT seniors.

\section{Conclusions}

As a result of constructing our $\mathrm{BCF}$, we have learned a number of lessons. First, having written out all the concepts covered by the core of our three versions of the Introductory Biology course at MIT and then organized them into a hierarchy, we were struck by the large number of concepts that we want our students to absorb. If they are to grasp and remember all of these concepts, we need to be explicit about what these concepts are, how they are connected to each other, and how they fit into the big picture of the course. We suggest that creating a hierarchical BCF with cross-references is a powerful way to organize the concepts and facts in order to promote their understanding as well as the understanding of their relationship to each other.

Creating a comprehensive BCF is a worthy and challenging task. We agree with Klymkowsky et al. (2003) that a community-wide discussion and consensus about the toplevel concepts is essential. "Designing curricula in a way that reflects the basic structure of a field of knowledge requires the most fundamental understanding of that field. It is a task that cannot be carried out without the active participation of the ablest scholars and scientists" (Bruner, 1960, p. 32). Therefore, it is possible that professional societies or professional development courses like the National Academies Summer Institute on Undergraduate Education in Biology could play a role in directing this discussion to ensure the inclusion of multiple perspectives (Wood and Gentile, 2003).

The creation of a hierarchical BCF has been a fascinating and enlightening process. The hierarchical structure of our BCF offers a number of benefits including the ability to rank concepts with respect to their relative importance and to highlight interconnections among different areas of biology. We suggest that the process of constructing a hierarchical concept framework would be useful for any teacher of biology and is applicable to any field of knowledge.

\section{ACCESSING MATERIALS}

All materials can be accessed at our Web site: the BCF, at http://web.mit.edu/bioedgroup/HBCF/CBE-Summer2004. htm; the Gene Regulation animation, at http://web.mit. edu/bioedgroup/animations.htm.

\section{ACKNOWLEDGMENTS}

The authors wish to thank the faculty of Introductory Biology courses at MIT, in particular, Robert Weinberg and Hazel Sive, the instructors for the Introductory Biology courses at MIT, and all the members of the HHMI Education Group for their help and advice in constructing the BCF. In particular, we thank Michelle Mischke for sharing the benefits of her extensive teaching experience and for all her help and encouragement. We also thank Megan Rokop for her close reading of and helpful suggestions for the BCF. This work and its authors were supported by an HHMI Professorship awarded to Graham C. Walker.

\section{REFERENCES}

American Association for the Advancement of Science. (1985). Project 2061: Benchmarks for Science Literacy. http://www.project2061.org/ tools/benchol/bolframe.html.

American Association for the Advancement of Science. (1989). Project 2061: Science for All Americans. http://www.project2061. org/tools/sfaaol/sfaatoc.htm.

American Association for the Advancement of Science and the National Science Teachers Association. (2003). Project 2061: Atlas of Science Literacy. http://www.project2061.org/tools/atlas/ default.htm. 
Anderson, D.L., Fisher, K.M., and Norman, G.J. (2002). Development and evaluation of the conceptual inventory of natural selection. J. Res. Sci Teach. 39, 952-978.

Audesirk, T., Audesirk, G., and Byers, B.E. (2002). Biology: Life on Earth, 6th ed, Upper Saddle River, NJ: Prentice Hall.

Bruner, J.S. (1960). The Process of Education, Cambridge, MA: Harvard University Press.

Cavallo, A.L. (1992). The retention of meaningful understanding of meiosis and genetics. Paper presented as a poster at the Annual Conference of the National Association for Research in Science Teaching. Boston, MA, March 22.

Deming, G. (2002). Results from the astronomy diagnostic test national project. Astron. Educ. Rev. 1(1). http://aer.noao.edu, posted June 14.

Hake, R. (1998). Interactive engagement versus traditional methods: A six-thousand-student survey of mechanics test data for introductory physics courses. Am. J. Phys. 66, 64-74.

Halloun, I., and Hestenes, D. (1985). The initial knowledge state of college physics students. Am. J. Phys. 53, 1043.

Hestenes, D., and Wells, M. (1992). A mechanics baseline test. Phys. Teach. 30(3), 159.

Hestenes, D., Wells, M., and Swackhamer, G. (1992). Force Concept Inventory. Phys. Teach. 30(3), 141-158.

Hoefnagels, M.H. (2002). Using superstitions and sayings to teach experimental design. Proc. 24th Conf. ABLE, 325-327.

Hufnagel, B. (2002). Development of the astronomy diagnostic test. Astron. Educ. Rev. 1(1). http:/ / aer.noao.edu, posted June 14.

Klymkowsky, M.W., Garvin-Doxas, K., and Zeilik, M. (2003). Bioliteracy and teaching efficacy: What biologists can learn from physicists. Cell Biol. Educ. 2, 155-161.

Landis, C.R., Ellis, A.B., Lisensky, G.C., Lorenz, J.K., Meeker, K., and Wamser, C.C. (2001). Chemistry ConcepTests: A Pathway to Interactive Classrooms, Upper Saddle River, NJ: PrenticeHall.

Mayer, R.E. (2002). Rote versus meaningful learning. Theory Pract. 41(4), 226-232.

National Research Council. (1996). National Science Education Standards, Washington, DC: National Academy Press. Available at http://www.nap.edu/readingroom/books/nses/html/.

National Research Council. (1999). Transforming Undergraduate Education in Science, Mathematics, Engineering, and Technology, Washington, DC: National Academy Press. Available at: http://nap.edu/ $\mathrm{html} /$ transund.
National Research Council. (2000). How People Learn: Brain, Mind, Experience, and School: Expanded Edition, eds. J.D. Bransford, A.L. Brown, R.R. Cocking, Washington, DC: National Academy Press. Available at: http://nap.edu/.

National Research Council. (2002). Bio2010: Transforming Undergraduate Education for Future Research Scientists, ed. L. Stryer, Washington, DC: National Academies Press. http://nap.edu/ catalog/10497.html?onpi_newsdoc09102002.

Novak, J.D. (1998). Learning, Creating, and Using Knowledge: Concept Maps as Facilitative Tools in Schools and Corporations, Mahwah, NJ. Lawrence Erlbaum.

Novak, J.D. (2002). Meaningful learning: The essential factor for conceptual change in limited or inappropriate propositional hierarchies leading to empowerment of learners. Sci. Educ. 86, 548-571.

Oliver, R., and Oliver H. (1997). Using context to promote learning from information-seeking tasks. J. Am. Soc. Inform. Sci. 48(6), 519526.

Purves, W.K., Sadava, D., Orians, G.H., and Heller, H.C. (2001). Life: The Science of Biology, 6th ed., Sunderland, MA: Sinauer Associates.

Shavelson, R.J., Baxter, G.P., and Pine, J. (1991). Performance assessment in science. Appl. Measure. Educ. 4(4); 347-362.

Solomon, E.P., Berg, L.R., and Martin, D.W. (2002). Biology, 6 ed., Monterey, CA: Brooks Cole.

SUNY, Ithaca College of Agriculture, Life Sciences at Cornell University. (1980). Handbook for the Learning How to Learn Program, Ithaca, NY: Cornell University.

Waern, Y. (1981). On the relation between comprehension and memory of a complex text. Scand. J. Educ. Res. 25, 21-37.

Whitehead, A.N. (1929). The Aims of Education, New York: Macmillan

Wiggins, G., and McTighe, J. (2000). Understanding by Design, Upper Saddle River, NJ: Merrill Education/Prentice Hall.

Wood, W.B. (2003). Inquiry-based undergraduate teaching in the life sciences at large research universities: A perspective on the Boyer Commission report. Cell Biol. Educ. 2, 112-116.

Wood, W.B., and Gentile, J.M. (2003). Teaching in a research context. Science. 302, 1510.

Zeilik, M. (2003). The birth of the Astronomy Diagnostic Test: Prototest evolution. Astron. Educ. Rev. 1(2). http:/ / aer.noao.edu, posted January 13, 2003.

Zeilik, M., Schau, C., Mattern, N., Hall, S., Teague, K.W., and Bisard, W. (1997), conceptual astronomy: A novel approach for teaching postsecondary science courses. Am. J. Phys. 65, 987. 